\title{
Time to Change campaign through the eyes of a service user. Invited commentary on Evaluation of England's Time to Change programme
}

\author{
Mary Nettle
}

\section{Summary}

The Time to Change campaign and its evaluation in this supplement are looked at from a service user's perspective. A number of achievements are applauded, but pertinent questions about the campaign analysis are raised and a qualitative evaluation is called for.

\section{Declaration of interest}

None.
As I understand it, the Time to Change programme is an attempt to educate and inform the public about mental health in order to combat stigma and discrimination. This should also make life easier for those living with a mental illness by changing attitudes of people they come into contact with and how they feel about themselves. The evaluation of this work programme was very comprehensive and covered public knowledge, attitudes and behaviour, service users' experience, newspaper coverage of mental illness, attitudes of employers, a social marketing campaign, attitudes of medical students and an economic evaluation. Services users were involved in some aspects of the evaluation such as commenting on the measures to be used and some interviewing.

The service user survey used for the evaluation had a very low response rate due to the way it found respondents. ${ }^{1}$ This should be looked at for future work. Despite this, it showed a reduction in discrimination between 2008 and 2011 for most of the 21 life areas mentioned. Four areas show an increase in discrimination: 'feeling safe', 'welfare benefits', 'marriage' and 'transport'. No analysis was given of why this might be. Unfortunately, there was also no attempt to analyse any qualitative information of how discrimination has manifested itself. Brief examples were given which could have been expanded.

Mental health-related knowledge, attitudes and behaviour were studied in the general public over time and it was found that Time to Change may have helped to change public attitudes and intended behaviour but not knowledge, demonstrated by survey questions, for example that medication can be an effective treatment for people with mental health problems. ${ }^{2}$

The analysis of newspaper articles showed an improvement over time and more use of first-person accounts by people with lived experience. Let us hope this trend continues. ${ }^{3}$

A telephone survey of employers showed how they had become far more aware that their employees may develop a mental health problem during their working life. ${ }^{4}$ In 2006, 31\% of employers thought that none of their employees would have a mental health problem during their working life, whereas in 2010 only $4 \%$ held that opinion. 'Stress' is used to describe mental health difficulties in the workplace and employers still appear uncomfortable discussing mental health with applicants or employees but seem more willing to make reasonable adjustments.
The influence of social marketing was a large component of the Time to Change programme. This was evaluated and included measuring the impact of television, cinema and press campaigns but did not seem to concern what many people think of as social marketing using technology, such as mobile phones and the internet and platforms such as Facebook and Twitter. ${ }^{5}$ The reasons for not including these forms of social marketing were not explained. Social marketing did include face-to-face contact events, although the content of these was not described. It was thought that there is a modest but positive and significant improvement, especially in measuring intended behaviour from the mass media component. The social contact events improved attitudes and willingness to challenge stigma and discrimination.

Another intervention evaluated as part of the Time to Change programme was brief training for medical students which included testimonies from people with lived experience of mental health problems and role-plays by professional actors taking on the roles of service users and carers. ${ }^{6}$ It would have been useful to find out why actors were playing these roles rather than 'real' people. There was a positive effect on attitudes - 'It provided an insight into mental health topics that their formal education had not provided' - but this did not last. Reasons as to why this positive effect did not endure were not established.

The economic evaluation of the Time to Change programme focused on how it affected employment for people with depression but the rationale for this was not explained. ${ }^{7}$ It found that for people with depression Time to Change was a potentially cost-effective and low-cost intervention. The majority of this evaluation made reference to the broad aims of the campaign and seemed to imply that the whole campaign was cost-effective, not just for people with depression.

Time to Change is a large programme with laudable aims of combating stigma and discrimination. All aspects of the programme have been evaluated and the measures used were comparable across all eight papers in this supplement. This evaluation programme relies heavily on statistical analysis which is necessary to be able to track progress over time. It would have been useful to have a qualitative element to bring the information to life and make it more real for those wanting Time to Change to make a difference to their lives. 
Mary Nettle, 50 Byfield Rise, Worcester WR5 1BA, UK. Email: menettle@yahoo.co.uk

\section{References}

1 Corker E, Hamilton S, Henderson C, Weeks C, Pinfold V, Rose D, et al. Experiences of discrimination among people using mental health services in England 2008-2011. Br J Psychiatry; 202 (suppl 55): s58-63.

2 Evans-Lacko S, Henderson C, Thornicroft G. Public knowledge, attitudes and behaviour regarding people with mental illness in England 2009-2012. Br J Psychiatry; 202 (suppl 55): s51-7.
3 Thornicroft A, Goulden R, Shefer G, Rhydderch D, Rose D, williams $P$, et al Newspaper coverage of mental illness in England 2008-2011. Br J Psychiatry; 202 (suppl 55): s63-9.

4 Henderson C, Williams P, Little K, Thornicroft G. Mental health problems in the workplace: changes in employers' knowledge, attitudes and practices in England 2006-2010. Br J Psychiatry; 202 (suppl 55): s70-6.

5 Evans-Lacko S, Malcolm E, West K, Rose D, London J, Rüsch N, et al. Influence of Time to Change's social marketing interventions on stigma in England 2009-2011. Br J Psychiatry; 202 (suppl 55): s77-88.

6 Friedrich B, Evans-Lacko S, London J, Rhydderch D, Henderson C, Thornicroft G. Anti-stigma training for medical students: the Education Not Discrimination project. Br J Psychiatry; 202 (suppl 55): s89-94.

7 Evans-Lacko S, Henderson C, Thornicroft G, Mccrone P. Economic evaluation of the Time to Change anti-stigma social marketing campaign in England 2009-2011. Br J Psychiatry; 202 (suppl 55): s95-101. 